\title{
Komposisi Perifiton Pada Daun Lamun Enhalus acoroides, Royle 1839 (Angiosperms : Hydrocharitaceae) dan Thalassia hemrpichii, Ascherson 1871 (Angiosperms : Hydrocharitaceae) di Perairan Teluk Awur, Jepara
}

\author{
Abdino Putra Utama*,Nirwani Soenardjo, Hadi Endrawati \\ Departemen IImu Kelautan, Fakultas Perikanan dan IImu Kelautan, Universitas Diponegoro \\ Jl. Prof.H.Soedarto S.H, Tembalang,Semarang, Jawa Tengah 50275 Indonesia \\ ${ }^{*}$ Corresponding author, e-mail : abdinoptr@gmail.com
}

\begin{abstract}
ABSTRAK: Perifiton merupakan salah satu organisme yang berkontribusi besar dalam meningkatkan produktivitas primer di ekosistem lamun. Kondisi padang lamun sangat menentukan keberadaan perifiton, sehingga pada kondisi lamun yang baik merupakan tempat yang layak untuk penempelan perifiton. Aktivitas antropogenik akan menyebabkan gangguan maupun kerusakan pada lamun sehingga mempengaruhi penempelan perifiton pada lamun. Perairan Teluk Awur dekat dengan kegiatan-kegiatan antropogenik yang dapat menyebabkan gangguan pada kondisi lingkungan sekitarnya. Penelitian ini bertujuan untuk mengetauhi jenis dan kelimpahan perifiton yang hidup pada lamun jenis Enhalus acoroides dan Thalassia hemprichii, serta kelimpahan perifiton pada tiap bagian daun (pangkal, tengah dan ujung). Pengambilan sampel daun lamun dilaksanakan Bulan November 2018 di Perairan Teluk Awur, Kabupaten Jepara. Identifikasi jenis lamun dilakukan pada lokasi penelitian, dan identifikasi jenis perifiton dilakukan pada laboratorium. Berdasarkan hasil penelitian bahwa, komposisi perifiton terdapat 6 kelas terdiri dari 23 genus dengan kelimpahan tertinggi selalu terdapat pada ujung daun. Genus yang paling sering ditemukan adalah Nitzschia. Kelimpahan perifiton pada lamun jenis E. acoroides dan T. hemprichii secara berturut - turut sebanyak 2689,33 individu/ $\mathrm{cm}^{2}$ dan 3158,67 individu/ $\mathrm{cm}^{2}$. Kelimpahan perifiton semakin meningkat ketika mendekati bagian ujung daun.
\end{abstract}

Kata kunci : Perifiton, Kelimpahan Perifiton, Ekosistem Lamun.

\section{Periphyton Composition On The Seagrass Leaves Enhalus acoroides, Royle 1839 (Angiosperms : Hydrocharitaceae) and Thalassia hemprichii, Ascherson 1871 (Angiosperm : Hydrocharitaceae) in Teluk Awur Waters, Jepara}

\begin{abstract}
Periphyton is one of the organism that contributes greatly in increasing primary productivity on seagrass ecosystems. Seagrass conditions greatly determine the presence of periphyton, so when a good seagrass conditions, it is a suitable place for periphyton attachment. Anthropogenic activity will cause disturbance and damage to seagrass, which affects the attachment of periphyton on seagrass. Teluk Awur waters are close to anthropogenic activities which can cause interference with the conditions of the surrounding environment. This study aims to determine the type and abundance of periphyton that lives on the types of seagrass leaves Enhalus acoroides and Thalassia hemprichii, as well as periphyton abundance in each part of the leaf (base, middle and tip).Sampling of seagrass leaves was carried out on November 2018 in Teluk Awur, Jepara Regency. Identification of seagrass species was carried out at the study site, and identification of the type of periphyton was carried out in the laboratory. Based on the results of the study, that on periphyton composition, 6 classes are consisting of 23 genera with the highest abundance always found at the tip of the leaf. The most common found genus is Nitzschia. Periphyton abundance in seagrass species $E$. acoroides and $T$. hemprichii respectively were $2689.33 \mathrm{Ind} / \mathrm{cm}^{2}$ and $3158,67 \mathrm{Ind} / \mathrm{cm}^{2}$. Periphyton abundance inceases as it approaches the tip of the leaves.
\end{abstract}

Keywords: Periphyton, Periphyton Abundance, Seagrass Ecosystem 


\section{PENDAHULUAN}

Perairan Jepara terletak pada $110^{\circ} 37^{\prime}$ E, $6^{\circ} 38 \mathrm{~S}$. kawasan ini memiliki 3 ekosistem dominan yaitu; padang lamun, mangrove dan terumbu karang. (Endrawati, 2000). Ketiga ekosistem tersebut merupakan penyangga bagi kehidupan laut dan darat. Berbagai biota bergantung pada 3 ekosistem tersebut. Sebagaimana mangrove dan terumbu karang, padang lamun juga merupakan ekosistem penting bagi kehidupan karena berperan sebagai produsen mata rantai (Kordi, 2011).

Ekosistem padang lamun yang tersebar luas di perairan dangkal sangat produktif dan berperan penting dalam kehidupan biota laut. Fungsi ekologisdari padang lamun adalah sumber utama produktivitas primer, sumber makanan (feeding ground), penstabil dasar perairan (trapping sediment), tempat perkembangbiakan (spawning ground), pengasuhan (nurseryground), peredam arus, penghasil oksigen dan mereduksi $\mathrm{CO}_{2}$ didasar perairan(Philips dan Menez, 2008). Salah satu organisme yang berkaitan erat dengan lamun adalah perifiton. Perifiton mempunyai peran dalam meningkatkan produktivitas primer perairan karena dapat melakukan proses fotosintesis dan dapat membentuk zat organik (Noviantiet al., 2013). Selain itu, perifiton juga dapat dijadikan bioindikator pencemaran karena dapat merespon perubahan lingkungan perairan.

Kontribusi komunitas perifiton terhadap produktivitas lebih besar daripada kontribusi fitoplankton. Wetzel (2001), produktivitas organik tahunan pada fitoplankton sebesar 5-15, sedangkan algae epifitik 10-60. Beberapa penelitian sebelumnya melaporkan bahwa perifiton berkontribusi $42-97 \%$ dari total produktivitas tahunan, terutama di perairan dangkal $(2-3 \mathrm{~m})$. Produktivitas seperti itu di lingkungan air dangkal menyediakan sumber makanan yang berlimpah, cepat diperbaharui, mudah berasimilasi yang bisa lebih penting daripada makrofit (Azim, 2009).Menurut Meskipun diakui penting, perifiton masih diabaikan sebagai kontributor utama sebagian besar nutrisi pada siklus ekologis akuatik (Saikiaetal., 2013).Sehingga diperlukan penelitian mengenai organisme perifiton yang memiliki peranan penting dalam ekosistem perairan laut dangkal. Berbagai upaya harus dilakukan demi menjaga kelestarian perifiton yaitu dengan menjaga substratnya (lamun), karena perkembangan perifiton tergantung pada kondisi substratnya.

Kondisi padang lamun sangat menentukan keberadaan perifiton, sehingga kondisi lamun yang baik merupakan tempat yang layak untuk penempelan perifiton. Aktivitas antropogenik seperti kapal nelayan, keberadaan pemukiman, penangkapan ikan, dan aktivitas lain yang akan menyebabkan gangguan maupun kerusakan pada lamun sehingga mempengaruhi penempelan perifiton pada lamun (Herlina, 2018). Perairan Teluk Awur dekat dengan kegiatan-kegiatan antropogenik seperti pembangunan kampus, tambak, dan kegiatan hatchery yang dapat menyebabkan gangguan pada kondisi lingkungan sekitarnya.

Semua jenis lamun dapat menjadi tempat penempelan perifiton. Perairan Teluk Awur, Jepara banyak ditemukan lamun dengan jenis Enhalus acoroides, Thalassia hemprichii, Cymodocea serrulata, C. rotundata dan Syringodium isoetifolium (Riniatsih, 2016). Jenis E. acoroides dan T. hemprichii akan dijadikan sampel penelitian karena memiliki perbedaan yang sangat jelas dari bentuk dan ukuran daunnya. Serta jenis ini banyak ditemukan di Perairan Teluk Awur

Penelitian ini bertujuan untuk mengetauhi jenis perifiton yang menempel pada lamun jenis $E$. acoroides dan $T$. hemrpichii, serta mengetahui kelimpahan perifiton pada kedua jenis lamun dan pada tiap bagian daun lamun (pangkal, tengah dan ujung.

\section{MATERI DAN METODE}

Materi yang digunakan pada penelitian ini adalah perifiton yang hidup menempel pada daun lamun. Alat yang digunakan untuk menunjang penelitian ini yaitu, peralatan untuk sampling lamun dan peralatan laboratorium untuk identifikasi jenis perifiton yang ditemukan

Jarak padang lamun dari bibir pantai diukur terlebih dahulu menggunakan roll meter sebelum dilakukannya pengambilan sampel daun lamun. Pengambilan sampel daun lamun dilakukan sebanyak 3 kali ulangan di setiap transek garis pengamatan sesuai dengan Sabrini et al., (2015). Sampel daun pada masing-masing transek diambil 1 tegakan pada lamun jenis Enhalus acoroides dan Thalassia hemprichii. Acuan yang digunakan untuk identifikasi jenis lamun menggunakan buku Status Padang Lamun Rahmawati et al., (2017).

Pengambilan sampel perifiton dilakukan menurut (Noviantiet al., 2013), helai daun lamun terluar 
diambil lalu dipotong sama rata menjadi 3 bagian (pangkal, tengah dan ujung). Setelah itu masingmasing bagian dipotong seluas $5 \times 2 \mathrm{~cm}^{2}$ diukur dari ujung daun. Potongan daun tersebut dimasukkan kedalam botol sampel yang sudah berisi air laut steril $20 \mathrm{ml}$ lalu dikerik menggunakan kuas. Setelah itu diberikan formalin $4 \%$ sebanyak 1 tetes.

Sampel perifiton dikocok agar merata lalu diambil dengan menggunakan pipet tetes ukuran $1 \mathrm{ml}$. Kemudian diteteskan pada Sedgewick rafter dan ditutup dengan cover glass. Pengamatan sampel dilakukan menggunakan mikroskop dengan perbesaran 100x dan identifikasi merujuk pada buku Illustrations of the Marine Plankton of Japan Yamaji (1984). Hasil pengamatan dicatat pada formulir perifiton. Kepadatan jenis perifiton dihitung berdasarkan perhitungan plankton, dengan modifikasi Lackey Drop Microtransecting Methods (APHA, 2005)

$$
K=\frac{N \times A t \times V t}{A c \times V s \times A s}
$$

Keterangan: $\mathrm{K}=$ Kelimpahan perifiton per satuan luas (ind/cm); At = Luas penampang permukaan ( $\left.\mathrm{mm}^{2}\right) ; \mathrm{Ac}=$ Luas amatan $\left(\mathrm{mm}^{2}\right) ; \mathrm{Vt}=$ Volume konsentrat dalam botol sampel contoh $(\mathrm{ml}) ; \mathrm{Vs}=$ Volume satuan tetes air contoh (ml); As = Luas bidang kerikan $\left(5 \times 2 \mathrm{~cm}^{2}\right) ; \mathrm{N}=$ Jumlah perifiton yang diamati

Indeks keanekaragaman jenis merupakan karakteristik dari suatu komunitas yang menggambarkan tingkat keanekaragaman jenis dari organisme yang terdapat dalam komunitas tersebut. Indeks keanekaragaman dapat dihitung dengan rumus sebagai berikut(Odum, 1971):

$$
H^{\prime}=-\sum_{n=1}^{s} p i \ln p i
$$

Keterangan: $\mathrm{H}^{\prime}$ = Indeks keanekaragaman; $\mathrm{S}=$ Banyaknya jenis; $\mathrm{Pi}=\mathrm{ni} / \mathrm{N} ; \mathrm{ni}=$ Jumlah individu spesies ke-i; $\mathrm{N}=$ Jumlah total individu

Kriteria indeks keanekaragaman Shannon-Wiener menurut Wilhm (1975) adalah sebagai berikut : $H^{\prime}<1=$ Keanekaragaman jenis rendah; $1<H^{\prime}<3=$ Keanekaragaman jenis sedang; $H^{\prime}>3=$ Keanekaragaman jenis tinggi

Indeks keseragaman menurut Odum (1971) dapat dihitung dengan menggunakan rumus sebagai berikut:

$$
e=\frac{H^{\prime}}{H^{\prime} \max }
$$

Keterangan: e = Indeks keseragaman evenness; $H^{\prime}$ = Indeks keanekaragaman Shannon; H' max = In S(jumlah genus)

Menurut Krebs (1985) besarnya indeks keseragaman suatu populasi berkisar 0 - 1 dengan kriteria sebagai berikut: $\mathrm{e}<0,4=$ Keseragaman jenis rendah; $0,4<\mathrm{e}<0,6=$ Keseragaman jenis sedang; $\mathrm{e}>0,6=$ Keseragaman jenis tinggi

Indeks Dominansi merupakan derajat pada dominasi dari satu, beberapa atau banyak jenis (Odum, 1971). Rumus Indeks Dominansi yaitu:

$$
C=-\sum_{i=1}^{s}\left(n i \frac{i}{N}\right)^{2}
$$

Keterangan: $\mathrm{C}=$ Indeks Dominansi; $\mathrm{N}=$ Jumlah total individu; $\mathrm{ni}=$ Jumlah individu jenis ke-i kriteria Indeks Dominansi Odum (1971) adalah sebagai berikut : $0<\mathrm{C}<0,5 \quad=$ Tidak ada jenis yang mendominasi; $0,5<\mathrm{C}<1=$ Terdapat jenis yang mendominasi 


\section{HASIL DAN PEMBAHASAN}

Berdasarkan hasil penelitian bahwa, komposisi perifiton terdapat 6 kelas terdiri dari 23 genus yaitu; Bacillariophyceae (15 genus yaitu Melosira, Skeletonema, Leptocylindrus, Coscinodiscus, Asterionela, Biddulphia, Flagilaria, Thalassiothrix, Synedra, Lichmopora, Coconeis, Navivula, Pleurosigma, Diploneis, Nitzschia). Cyanophyceae (2 genus yaituOscillatora dan Anabaena). Dinophyceae (2 genus yaitu Dinophysis dan Peridinium), Gastropoda (1 genus Limacina) Rhizopoda (1 genus yaitu Globorotalia), Copepoda (2 genus yaitu Calanus dan Oncaea).

Jenis perifiton yang paling sering ditemukan pada lokasi penelitian yaitu dari kelas Bacillariophyceae karena merupakan kelas mikroalga yang memiliki kemamupan adaptasi terhadap lingkungan. Sesuai dengan penyataan Perry et al, (2003), bahwa Bacillariophyceae memiliki ketahanan yang tinggi serta mampu beradaptasi pada lingkungan yang fluktuatif, karena sturktur dinding sel yang kuat. Hal ini ditambahkan oleh Omori dan Ikeda (1992) bahwa, kelas Bacillariophyceae mendominasi di perairan. Epifit (perifiton) yang utama pada lamun adalah kelas Bacillariophyceae terutama jenis Nitzschia (Harlin, 1980). Dilihat dari siklus hidupnya, kelas tersebut mampu berkembang biak dengan cepat sehingga mampu mendominasi di antara jenis lainnya. Sesuai dengan pernyataan Nybakken (1998) bahwa, laju penggandaan sel diatom berlangsung sekitar 0.5 sampai $6 \mathrm{sel} /$ hari. Keberadaan kelompok Bacillariophyceae di perairan memang sering mendominasi dan memiliki kelimpahan yang tinggi kecuali pada sungai yang berlumpur (Junda et al., 2013).

Komposisi perifiton yang ditemukan selain mikroalgae juga ada beberapa zooplankton. Keberadaannya diduga sedang mencari makan, karena makanan utama zooplankton merupakan mikroalgae. Gastropoda ditemukan menempel pada bagian tengah dan pangkal daun. Jenis tersebut bergerak dari bawah dan menempel pada daun untuk mencari makan. Padang lamun termasuk salah satu kawasannursery ground dan feeding ground yang merupakan tempat berlindung sekaligus mencari makan bagi hewan-hewan kecil. Sesuai dengan pernyataan Kiswara (1997) bahwa, padang lamun diketahui mendukung berbagai rantai makanan, baik didasari oleh herbivora maupun detrivor.

Kelimpahan total perifiton yang didapat dari daun lamun jenis Enhalus acoroides dan Thalassiahemprichii secara berturut - turut yaitu 2689,33 individu $/ \mathrm{cm}^{2}$ dan 3158,67 individu $/ \mathrm{cm}^{2}$. Serta kelimpahan perifiton pada bagian ujung daun lamun relatif paling banyak. Kelimpahan perifiton pada genus yang ditemukan di masing-masing bagian daun tersaji pada Gambar 1.

Kelimpahan perifiton pada kedua jenis lamun di lokasi penelitian relatif tinggi. Diduga pada kerapatan lamun yang tinggi dapat dengan mudah ditempeli, karena organisme yang terbawa arus akan tertahan atau terperangkap oleh padang lamun. Jika kerapatan lamun rendah maka perifiton yang terbawa arus akan sulit tertahan atau terperangkap oleh daun lamun lainnya. Menurut Alhanif (1996), pada umumnya kelimpahan setiap genus perifiton meningkat pada kerapatan lamun yang semakin tinggi. Substrat padang lamun di lokasi penelitian termasuk pasir berlumpur. Jenis substrat tersebut sangat mudah untuk terangkat. Diduga dapat menyebabkan proses penempelan perifiton di bagian tengah dan pangkal terhambat karena terhalang oleh partikel-partikel lain. Sesuai dengan pernyataan Wood dan Armitage (1997), sedimentasi dapat mencegah melekatkan mikroalga ke substrat, dalam kasus ekstrem dapat menghilangkan perifiton dan makrofit. Meskipun sedimentasi tidak memiliki pengaruh yang mencolok pada kelimpahan perifiton seperti faktor fisik lainnya, tingkat sedimentasi yang tinggi dapat menghancurkan seluruh struktur komunitas di dalam air.(Wu, 2017). Plankton merupakan organisme yang hidup melayang di permukaan perairan, sehingga memudahkan organisme tersebut untuk menempel pada ujung daun lamun dimana ujung daun merupakan bagian lebih dekat dengan permukaan perairan.Bagian ujung daun merupakan bagian paling atas dan intensitas cahaya cenderung tinggi, oleh sebab itu proses fotosintesis dari perifiton autotrof berjalan dengan baik. Peristiwa tersebut sesuai dengan pernyataan Ismail (2016) bahwa, perifiton yang menempel di dominasi pada bagian ujung daun, karena ujung daun mendapatkan intensitas cahaya yang cenderung tinggi dan menyebabkan proses fotosintesis berjalan dengan baik.

Bagian pangkal dan tengah daun ditemukan beberapa gastropoda dan copepoda. Diduga menurunnya kelimpahan perifiton karena adanya peristiwa pemangsaan dari ikan-ikan kecil atau biota lain yang memanfaatkan ekosistem lamun sebagai tempat mencari makan (feeding ground). Grazing yang berat oleh hewan (larva serangga, kepiting, dan ikan tertentu) dapat mengakibatkan penurunan biomassa perifiton, perubahan tingkat produktivitas primer, perubahan komposisi taksonomi dan struktur komunitas perifiton (Christofoletti et al., 2011). Ismail (2016) menambahkan bahwa pada 
bagian tengah daun sering dijumpai bekas gigitan ikan-ikan kecil, yang menyebabkan kelimpahan perifiton lebih sedikit.

Berdasarkan hasil analisa Indeks Keanekaragaman, Indeks Keseragaman dan Indeks Dominansi yang tersaji pada Tabel 1. menunjukan bahwa, tidak ada perbedaan struktur komunitas perifiton antara lamun jenis $E$. acoroides dengan $T$. hemprichii. Sama halnya dengan bagian daun lamun terlihat bahwa tidak ada perbedaan struktur komunitas perifiton. Komunitas perifiton yang ditemukan lebih banyak dari kelompok alga. Sehingga kondisi lingkungan sangat mempengaruhi struktur komunitas.

Kondisi cuaca cerah membuat intensitas cahaya yang masuk tinggi. Cahaya merupakan salah satu pengamatan umum dalam ekologi, karena laju produksi biomassa dan kepadatan autotrof meningkat oleh cahaya. Cahaya adalah faktor utama dalam ekologi, karena dengan adanya cahaya dapat mempengaruhi suhu dan pertumbuhan organisme (Rutherford et al., 1997). Kondisi padang lamun di Perairan Teluk Awur, Jepara memiliki kanopi terbuka, Menurut Cashman et al., (2013) bahwa, ketersediaan cahaya yang banyak pada kanopi terbuka menghasilkan biomassa perifiton yang lebih besar serta suhu air akan meningkat. Suhu pada lokasi penelitian berkisar antara $31,6-36,8^{\circ} \mathrm{C}$.

Kondisi seperti itu kegiatan fotosintesis dari alga berjalan secara optimal dan menyebabkan struktur komunitas yang merata. Sesuai dengan pernyataan Baulch et al., (2005) bahwa, peningkatan suhu memiliki pengaruh besar pada proses utama komunitas perifiton seperti respirasi dan fotosintesis. Menurut Effendi, (2003) alga dari filum Chlorophyta dan diatom akan tumbuh baik pada kisaran $30^{\circ} \mathrm{C}-35^{\circ} \mathrm{C}$, dan filum Cyanophyta dapat bertoleransi terhadap kisaran suhu di atas $30^{\circ} \mathrm{C}$.

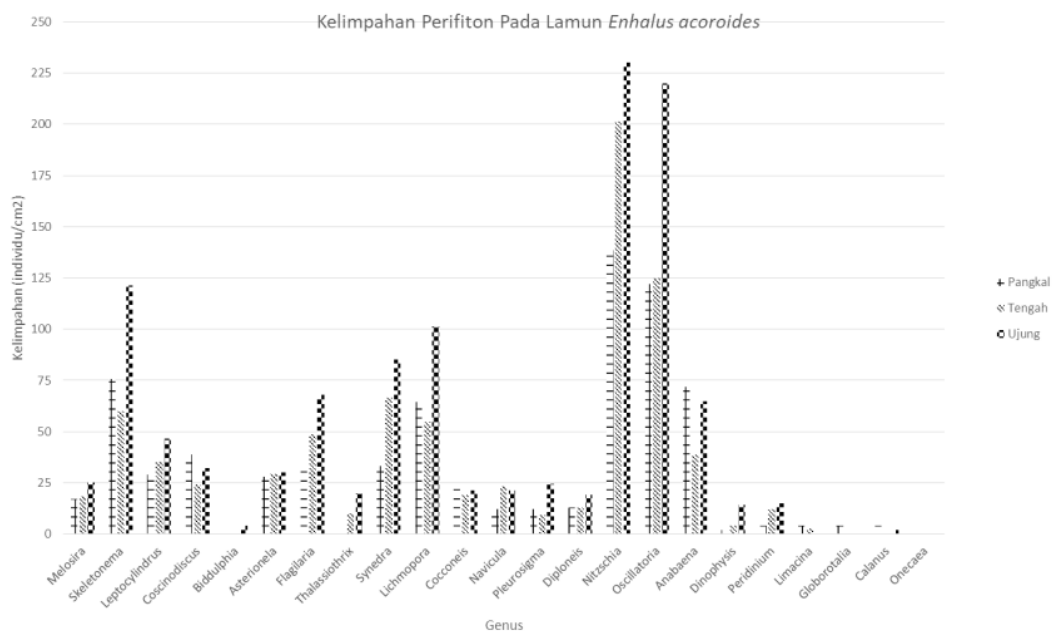

Gambar 1. Kelimpahan Genus Perition Pada Enhalus acoroides Perairan Teluk Awur, Jepara

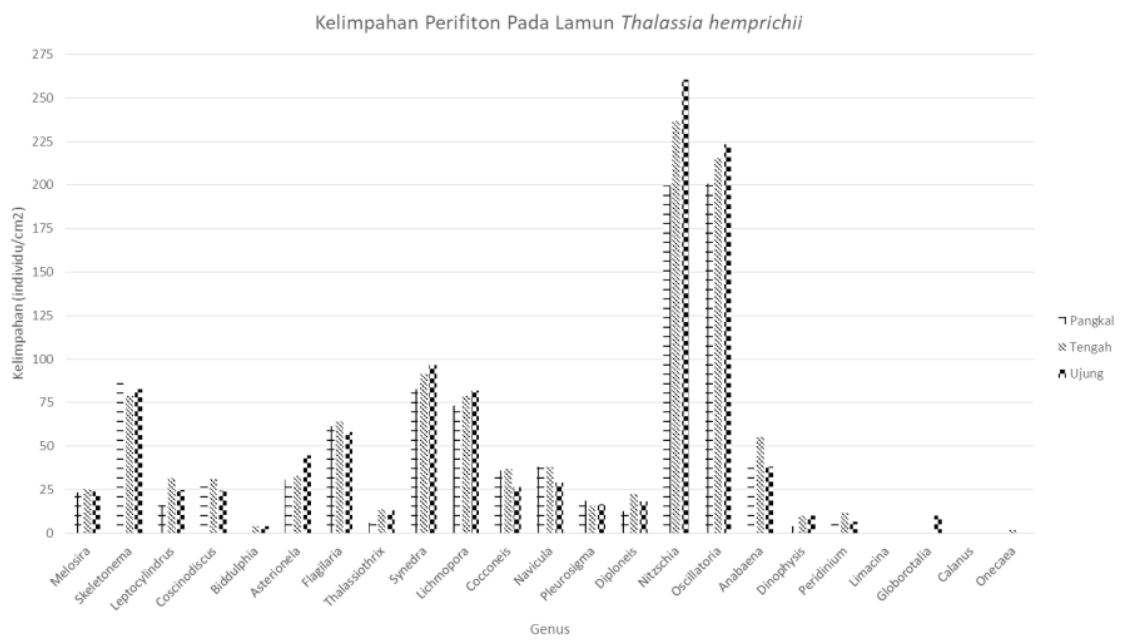

Gambar 2. Kelimpahan Genus Perifiton Pada Thalassia hemprichii Perairan Teluk Awur, Jepara 
Tabel 1. Indeks Keanekaragaman (H'), Indeks Keseragaman (e) dan Indeks Dominansi (C) Perifiton

\begin{tabular}{|c|c|c|c|c|c|c|c|}
\hline \multirow{2}{*}{ Indeks } & \multicolumn{3}{|c|}{ Enhalus acoroides } & \multicolumn{3}{|c|}{ Thalassia hemprichii } & \multirow{2}{*}{ Kategori } \\
\hline & Pangkal & Tengah & Ujung & Pangkal & Tengah & Ujung & \\
\hline$H^{\prime}$ & 2,418 & 2,420 & 2,469 & 2,365 & 2,475 & 2,401 & Sedang \\
\hline e & 0,874 & 0,849 & 0,844 & 0,849 & 0,851 & 0,826 & Tinggi \\
\hline C & 0,126 & 0,151 & 0,156 & 0,151 & 0,149 & 0,174 & $\begin{array}{l}\text { Tidak ada } \\
\text { dominansi }\end{array}$ \\
\hline
\end{tabular}

\section{KESIMPULAN}

Berdasarkan hasil pengamatan komposisi perifiton di Perairan Teluk Awur, Jepara, 6 kelas yang terdiri dari 23 genus yaitu, Bacillariophyceae (15 genus), Cyanophyceae (2 genus), Dinophyceae (2 genus), Gastropoda (1 genus), Rhizopoda (1 genus) dan Copepoda (2 genus). Jenis yang paling sering di temukan adalah Nitzschia. Kelimpahan perifiton pada lamun jenis Enhalus acoroides dan Thalassia hemprichiisecara berturut - turut sebanyak 2689,33 individu/cm² dan 3158,67 individu/ $\mathrm{cm}^{2}$. Kelimpahan perifiton meningkat ketika mendekati bagian ujung daun.

\section{UCAPAN TERIMAKASIH}

Artikel ini merupakan bagian dari skripsi yang berjudul "Kelimpahan Perifiton pada Daun Lamun Enhalus Acoroides dan Thalassia Hemrpichii di Perairan Teluk Awur, Jepara" untuk memperoleh gelar Sarjana Strata Satu Program Studi IImu Kelautan, Fakultas Perikanan dan IImu Kelautan Universitas Diponegoro.

\section{DAFTAR PUSTAKA}

APHA. 2005. Standard Methods for the Eamination of Water and Wastewater. United Book Press Inc. Baltimore, Maryland.

Azim, M.E., 2009. Photosynthetic periphyton and surfaces. In: Likens, G.E. (Ed.), Encyclopedia of Inland Waters. Academic Press, Oxford, pp. 184-191.

Baulch, H.M., Schindler, D.W., Turner, M.A., Findlay, D.L., Paterson, M.J. \& Vinebrooke, R.D., 2005. Effects of warming on benthic communities in a boreal lake: implications of climate change. Limnology and Oceanography, 50(5):1377-1392.

Cashman, M.J., Wehr, J.D. \& Truhn, K., 2013. Elevated light and nutrients alter the nutritional quality of stream periphyton. Freshwater Biology, 58(7):1447-1457

Christofoletti, R.A., Almeida, T.V. \& Ciotti, A.M., 2011. Environmental and grazing influence on spatial variability of intertidal biofilm on subtropical rocky shores. Marine Ecology-Progress Series 424:15-23

Effendi H. 2003. Telaah kualitas air Bagi Pengeloaan dan sumberdaya lingkungan. Kanisius. Yogyakarta.

Endrawati, H., Muhammad, Z. \& Hariyadi. 2000. The Abdundance Of Zooplankton as Secondary Producer At Awur Bay In The Northen Central Java Sea. Journal of Coastal Development. 1(1):13-23.

Harlin, M.M. 1980. Seagrass: A Resource Unknown in The Asean Region Association Of Southeast Asian Nation United State Coastal Resources Management Project Educations Series 6. Klarm. Manila. Philipinnes.

Herlina, Nora, I. \& S. Ikha.2018. Diversitas Mikroalga Epifit Berasosiasi pada Daun Lamun Thalassia hemprichii di Pulau Lemukutan Kalimantan Barat. Jurnal Laut Khatulistiwa. 2:3744

Junda, M, \& Yusminah, H . 2013. Identifikasi Perifiton Sebagai Penentu Kualitas Air Pada Tambak Ikan Nila (Oreochromis niloticus), Bionature, 14(1): 16 - 24. 
Kiswara W.1997. Inventarisasi dan evaluasi sumberdaya Pesisir : Struktur Komunitas Padang Lamun di Teluk Banten. Makalah Kongres Biologi Indonesia XV. Jakarta, Indonesia.

Kordi, K.H.G.M. 2011. Ekosistem Lamun (seagrass) Fungsi, Potensi, Pengelolaan. Jakarta: Rineka Cipta, 191 hal.

Krebs, C. L. 1985. Ecological Methodology. Harper and Row Publisher, London. 694 p.

Novianti, M., Widyorini, N. \& Suprapto, J. 2013. Analisis Kelimpahan Perifiton Pada Kerapatan Lamun Yang Berbeda Di Perairan Pulau Panjang, Jepara. Journal of Management of Aquatic Resources, 2(3): $219-225$

Nybakken, J. W. 1998. Biologi Laut: Suatu Pendekatan Ekologi. Gramedia. Jakarta.

Odum, E.P. 1971. Dasar-dasar Ekologi. Ed.2. W. B. Saunders Company. Philadelphia and London. HIm. 574

Omori, M and T. Ikeda, 1992. Method in Marine Zooplankton Ecology. Krieger Pub Co. 332p.

Perry, R. 2003. A Guide to Marine Phytoplankton of Southern California. University of California Press. USA.

Philips, R.C. \& Menez, E.G. 2008. Seagrasses. Smithsinian Contributions to the Marine Sciences, no. 34. Smithsonian Institution Press, Washington, D. C.

Rahmawati, S.,H. Indarto, M.H. Azkab dan W. Kiswara, 2017. Panduan Monitoring Padang Lamun. Pusat Penelitian Oseanografi LIPI, Jakarta, 34 hal.

Riniatsih, I. 2016. Distribusi Jenis Lamun Dihubungkan dengan Sebaran Nutrien Perairan di Padang Lamun Teluk Awur Jepara. Jurnal Kelautan Tropis 19(2):101-107.

Rutherford, J.C., Blackett, S., Blackett, C., Saito, L., Davies-Colley, R.J., 1997. Predicting the effects of shade on water temperature in small streams. New Zealand Journal of Marine and Freshwater Research 31 (5): 707-721.

Sabrini, R., Nugraha Y., Kuslani H. 2015. Teknik Sampling dan Pengamatan Perifiton di Ekosistem Lamun, Kepulauan Karimun Jawa, Jawa Tengah. Balai Taman Nasional Karimun Jawa 13(2):91-95

Saikia, S., Nandi, S., Majumder, S., 2013. A review on the role of nutrients in development and organization of periphyton. Journal of Research in Biology, 3(1): 780-788.

Wetzel, R.G. 2001. Limnology. Structure And Productivityof Aquatic Ecosystems.Pg132-133 Academic Press,San Diego California,USA.

Wilhm, J. F. (1975). Biological Indicator of Pollution. London: Blackwell Scientific Publications.

Wood, P.J. \& Armitage, P.D. 1997. Biological Effects of Fine Sediment in the Lotic Enviroment. Environmental Management, 21(2):203-17

Wu, Y. 2017. Periphyton: Functions and Application in Enviromental Remediation. Elsevier. Cambrigde : United States.

Yamaji. I. 1984. Illustrations of the Marine Plankton of Japan. Hoikusha. Japan. 